\title{
EDUKASI DARING REDUCE, REUSE, RECYCLE GUNA MENINGKATKAN PENGETAHUAN MASYARAKAT RT.02 DESA BUNIPAH MENGENAI PENGELOLAAN SAMPAH
}

\author{
Siti Hasanah ${ }^{11}$, Muhammad Arwi Firdaus ${ }^{1}$, Devi Norsari ${ }^{1)}$, Norbaiti1) \\ 1)Program Studi Kesehatan Masyarakat, Fakultas Kedokteran, Universitas Lambung Mangkurat, Banjarbaru, \\ Kalimantan Selatan, Indonesia \\ Corresponding author : Siti Hasanah \\ E-mail : 1810912320021@mhs.ulm.ac.id
}

Diterima 10 Juni 2021, Direvisi 23 Juli 2021, Disetujui 23 Juli 2021

\begin{abstract}
ABSTRAK
Sampah merupakan permasalahan global yang terjadi di hampir seluruh lapisan masyarakat, termasuk di komunitas RT.02 Desa Bunipah Kecamatan Aluh-Aluh Kabupaten Banjar yang disebabkan karena pengetahuan dan kemauan masyarakat masih rendah serta perilaku masyarakat yang keliru dalam mengelola sampah. Upaya yang dapat dilakukan untuk menanganai permasalahan tersebut adalah dengan memberikan edukasi pada masyarakat mengenai pengelolaan sampah. Tujuan dari kegiatan tersebut adalah untuk meningkatkan pengetahuan responden yang telah menerima informasi dari materi yang sudah dibagikan melalui media melalui booklet dan video. Metode kegiatan dilaksanakan secara daring dengan menggunakan platform Whatsapp. Adapun sasaran dari kegiatan ini adalah perwakilan masyarakat di RT.02 Desa Bunipah, Kecamatan Aluh-Aluh Kabupaten Banjar yang berjumlah 10 orang. Berdasarkan hasil pelaksanaan intervensi pada 10 responden, diketahui bahwa peningkatan pengetahuan sebanyak $10,7 \%$. Nilai rata-rata yang didapatkan responden saat pre-test adalah 84, sedangkan pada post-test adalah 93 yang berarti ada kenaikan pada saat pre-test maupun post-test mengenai pengelolaan sampah. Hasil ini diharapkan dengan bertambahnya pengetahuan sasaran dapat menumbuhkan kesadaran mengenai pentingnya menjaga kebersihan lingkungan seperti tidak membuang sampah sembarangan dan melakukan pengelolaan sampah secara mandiri sehingga dapar memberikan edukasi kepada kerabat atau orang terdekat agar permasalahan sampah di RT.02 Desa Bunipah dapat teratasi.
\end{abstract}

Kata-kata kunci: edukasi; pengetahuan; pengelolaan sampah

\begin{abstract}
Garbage is a global problem that occurs in almost all levels of society, including in the RT.02 community, Bunipah Village, Aluh-Aluh District, Banjar Regency, which is caused by low knowledge and willingness of the community and people's wrong behavior in managing waste. Efforts that can be made to deal with these problems are by educating the public about waste management. The purpose of this activity is to increase the knowledge of respondents who have received information from the material that has been distributed through the media through booklets and videos. The activity method is carried out online using the Whatsapp platform. The target of this activity is community representatives in RT. 02 Bunipah Village, Aluh-Aluh District, Banjar Regency, totaling 10 people. Based on the results of the intervention on 10 respondents, it is known that the increase in knowledge is $10.7 \%$. The average value obtained by the respondents during the pre-test was 84 , while the post-test was 93 , which means there was an increase in the pre-test and post-test regarding waste management. It is hoped that with the increase in target knowledge, it can raise awareness about the importance of maintaining environmental cleanliness such as not littering and managing waste independently so that it can provide education to relatives or closest people so that the waste problem in RT.02 in Bunipah Village can be resolved.
\end{abstract}

Keywords: education; knowledge; waste management

\section{PENDAHULUAN}

Sampah merupakan sisa kegiatan sehari-hari manusia atau proses alam yang berbentuk padat dan menjadi permasalahan secara global bakan hingga hari ini. Berdasarkan data sciencemag produksi sampah dunia tahun 2015 ada sebanyak 381 juta ton pertahun, dan selalu mengalami peningkatan dengan rata-rata 5,8 ton pertahun. Berdasarkan Statistik Lingkungan Hidup RI tahun 2016, jumlah timbunan sampah di Indonesia sudah mencapai 65,2 juta ton 
pertahun. Senada dengan hal tersebut, kondisi yang sama juga terjadi di Kalimantan Selatan. Dilansir dalam Media Indonesia berdasarkan informasi dari Kepala Bidang Pengelolaan Sampah Dinas Lingkungan Hidup Kalsel volume sampah yang diproduksi Kalsel perharinya mencapai 2.100 ton atau 766 ribu ton setahun dan dari jumlah itu $14 \%$ nya adalah sampah plastik yang diperkirakan sebesar 295,6 ton perhari atau 107 ribu ton setahun. Kemudian Menurut Kasi Penanganan dan Pengangkutan Sampah Dinas Lingkungan Hidup Kabupaten Banjar menyatakan bahwa Kabupaten Banjar memproduksi rata-rata sebesar $99.870 \mathrm{~kg}$ volume sampah yang diangkut setiap harinya atau 2.970 ton per bulan. Jumlah sampah ini dipastikan akan terus meningkat seiring bertambahnya jumlah penduduk. Sejalan dengan itu, permasalahan lingkungan dan kesehatan akibat sampah serta limbah juga bertambah (Kahfi, 2017).

Permasalahan sampah seringkali disebabkan karena perilaku manusia yang minim menerapkan Reduce, Reuse, Recycle atau yang secara umum dikenal sebagai metode 3R dalam pengelolaan sampah. Kondisi ini disebabkan karena pengetahuan dan kemauan masyarakat masih rendah serta perilaku masyarakat yang keliru dalam mengelola sampah. Kondisi ini juga terjadi di komunitas masyarakat di RT.02 Desa Bunipah Kecamatan Aluh-Aluh Kabupaten Banjar Provinsi Kalimantan Selatan. Hasil studi awal yang dilakukan pada bulan Januari untuk mengetahui metode pengolahan sampah di lokasi tersebut diketahui bahwa $66 \%$ diantaranya memilih untuk membuang sampah ke sungai, 26,86\% mengeleminasi sampah dengan membakarnya dan 7,14\% memilih untuk mengubur sampah. Penelusuran lebih dalam diketahui bahwa salah satu faktor yang menjadi penyebab perilaku masyarakat tersebut adalah masih minimnya keterpaparan informasi mengenai teknik pengelolaan sampah di tingkat rumah tangga sehingga masyarakat bingung dalam mengelola sampah dan memilih cara paling mudah yaitu membuang sampah ke badan sungai, membakar atau menguburnya (Wardany, 2020).

Kondisi ini akan membawa dampak yang negatif, dari sudut pandang estetika (kebersihan dan keindahan) maupun dari sudut sanitasi (kesehatan lingkungan). Tumpukan sampah yang tersebar tanpa mengenal tempat, memberikan kesan jorok, kotor, dan kumuh. Sementara dari sudut pandang kesehatan (lingkungan), keberadaan sampah dapat menjadi media berkembang biaknya bibit penyakit maupun menjadi media perantara menyebarluasnya suatu penyakit. Hal ini akan menjadi tempat yang subur bagi mikroorganisme patogen yang berbahaya bagi kesehatan manusia, dan juga menjadi tempat sarang lalat, tikus dan hewan liar lainnya. Pembakaran sampah dapat berakibat terjadinya pencemaran udara yang dapat mengganggu kesehatan masyarakat, dan memicu terjadinya pemanasan global, dan berbagai penyakit pernapasan. Kemudian pembusukan sampah dapat menimbulkan bau yang tidak sedap dan berbahaya bagi kesehatan. Cairan yang dikeluarkan dapat meresap ketanah, dan dapat menimbulkan pencemaran sumur, air tanah, dan yang dibuang ke badan air akan mencemari sungai. Pembuangan sampah kesungai atau badan air dapat menimbulkan pendangkalan sungai, sehingga dapat memicu terjadinya banjir (Mahyudin, 2017). Selain itu, kandungan dalam sampah dapat menyebabkan berbagai ganguan kesehatan apabila terjadi kontak langsung dengan manusia gangguan tersebut dapat terjadi pada pencernaan dan pada bagian pernafasan karena setiap sampah yang dihasilkan dapat mengandung berbagai macam bahan beracun seperti logam berat, insektisida dan lain sebagainya (Ramawati, 2020).

Salah satu upaya yang dapat dilakukan adalah dengan memperkaya informasi melalui promosi kesehatan dalam rangka meningkatkan pengetahuan masyarakat mengenai pengelolaan sampah. Disebabkan keterbatasan selama masa pandemic COVID19, teknik yang dapat diterapkan adalah dengan pemberian edukasi melalui booklet dan video dan disebarluaskan menggunakan media sosial Whatsapp pada masyarakat. Metode ini dipilih karena dianggap tepat untuk dilakukan serta penyebarluasan informasi dapat menjangkau seluruh masyarakat di RT.02 Desa Bunipah. Melalui edukasi tersebut, diharapkan dapat mencapai target luaran kegiatan seperti terjadinya peningkatan pengetahuan serta adanya perubahan sikap masyarakat.

Secara teori, metode pemberian edukasi menggunakan media video menurut Azhar Arsyad (2014) yang menyebutkan bahwa informasi yang disajikan melaui media ini berbentuk dokumen yang hidup, dapat dilihat dari layar monitor atau ketika diproyeksikan ke layar lebar melalui overhead projector dan dapat didegar suaranya, dilihat gerakanya (video atau animasi). Media bertujuan untuk menyajikan informasi dalam bentuk yang menyenangkan, menarik, mudah dimengerti dan jelas, informasi akan mudah dimengerti karena sebanyak mungkin indera, terutama telinga dan mata, digunakan untuk menyerap informasi itu (Bibit, 2013). 
Hal ini sejalan dengan penelitian Bibit Sulasto tentang efektivitas penggunaan media pembelajaran video untuk mencapai tujuan pembelajaran, yang hasil penelitiannya menyatakan bahwa dengan menggunakan media vidio pembelajaran lebih efektif dan dapat meningkatkan keberhasilan siswa dalam belajar, dibandingkan dengan metode ceramah ini dibuktikan dari peningkatan hasil nilai ratarata kelas ekperimen dan kelas kontrol. Penelitian lain oleh Sabarudin dkk (2020) juga menyebutkan faktor-faktor yang mempengaruhi keberhasilan sosialisasi online yaitu faktor individu, penyajian materi video dan leaflet, pemilihan kata yang digunakan, visualisasi pada media leaflet dan video serta audio yang digunakan pada media video. Adapun hasil penelitiannya menyebutkan bahwa efektivitas terhadap metode edukasi ini disajikan dimana berdasarkan nilai median bahwa penggunaan leaflet sekaligus video lebih tinggi dibandingkan dengan penggunaan leaflet saja terhadap peningkatan pengetahuan Masyarakat Kota Baubau tentang pencegahan Covid-19. Hal ini dimungkinkan karena pada penggunaan dua media sekaligus (video dan leaflet), responden terpapar dua kali terhadap informasi yang diberikan (Sabarudin dkk, 2020).

Menurut Ewles (1994) media booklet memiliki keunggulan, yaitu: Klien dapat menyesuaikan dari belajar mandiri; Pengguna dapat melihat isinya pada saat santai; Informasi dapat dibagi dengan keluarga dan teman; Mudah dibuat, diperbanyak dan diperbaiki serta mudah disesuaikan; Mengurangi kebutuhan mencatat; Dapat dibuat secara sederhana dengan biaya relatif murah; Awet; Daya tampung lebih luas; Dapat diarahkan pada segmen tertentu (Hapsari 2013). Penelitian Lia Artika (2017) mengenai efektivitas media booklet dan leaflet terhadap pengetahuan remaja putri tentang dampak kehamilan remaja menunjukkan hasil setelah diberikan media booklet, terbukti bahwa kelompok eksperimen dengan media booklet memiliki peningkatan pengetahuan terhadap dampak kehamilan remaja yang lebih bermakna dibandingkan kelompok eksperimen dengan leaflet (Sari, 2017).

Seluruh rangkaian kegiatan edukasi
secara daring ini diharapkan dapat menumbuhkan kesadaran mengenai meningkatkan pengetahuan dalam melakukan pengelolaan sampah secara mandiri bagi masyarakat, serta dapat menciptakan kebijakan mengenai pengelolaan sampah agar dapat mengatasi permasalahan sampah yang terjadi khususnya di RT.02 Desa Bunipah oleh pemerintah setempat, sehingga permasalahan sampah di RT.02 Desa Bunipah dapat teratasi dengan baik.

\section{HASIL DAN PEMBAHASAN}

Karakteristik responden yang mengikuti kegiatan promosi kesehatan adalah sebagai berikut.

Tabel 1. Karakteristik responden

\begin{tabular}{|c|c|c|}
\hline VARIABEL & $\begin{array}{l}\text { JUMLAH } \\
\text { (10 orang) }\end{array}$ & PERSENTASE \\
\hline \multicolumn{3}{|l|}{ Jenis Kelamin } \\
\hline 1. Laki-Laki & 4 & $40 \%$ \\
\hline 2. Perempuan & 6 & $60 \%$ \\
\hline \multicolumn{3}{|l|}{ Usia } \\
\hline 1. $<25$ Tahun & 2 & $20 \%$ \\
\hline \multicolumn{3}{|l|}{ Pendidikan } \\
\hline 1. SMP/Sederajat & 2 & $20 \%$ \\
\hline 2. SMA/Sederajat & 3 & $30 \%$ \\
\hline 3. D3 & 1 & $10 \%$ \\
\hline 4. $\mathrm{S} 1$ & 4 & $40 \%$ \\
\hline \multicolumn{3}{|l|}{ Pekerjaan } \\
\hline 1. Aparat Desa & 1 & $10 \%$ \\
\hline $\begin{array}{l}\text { Pegawai } \\
\text { 2. Negeri Sipil }\end{array}$ & 2 & $20 \%$ \\
\hline 3. Honorer & 1 & $10 \%$ \\
\hline 4. Karyawan & 2 & $20 \%$ \\
\hline 5. Pedagang & 3 & $30 \%$ \\
\hline Ibu Rumah & 1 & $10 \%$ \\
\hline 6. $\quad$ Tangga & & \\
\hline \multicolumn{3}{|l|}{ Pendapatan } \\
\hline Dibawah UMP & 6 & $60 \%$ \\
\hline 1. $<\mathrm{Rp}$ & & \\
\hline 2.877 .448 & & \\
\hline $\begin{array}{l}\text { Diatas UMP } \geq \\
\text { 2. } R p 2.877 .448\end{array}$ & 4 & $40 \%$ \\
\hline
\end{tabular}

Berdasarkan tabel diatas diketahui bahwa sebagian besar responden berjenis kelamin perempuan sebanyak 6 orang dengan persentase $60 \%$, usia responden paling banyak berumur $\geq 25$ Tahun yaitu sebanyak 8 orang (80\%). Adapun pendidikan dari responden yang terbanyak adalah lulusan S1 yaitu ada 4orang $(40 \%)$ dan pekerjaa responden terbanyak adalah bekerja sebagai pedagang yaitu ada 3 orang $(30 \%)$ serta penghasilan responden sebagian besar di bawah UMP < Rp 2.877.448 yaitu sebanyak 6 orang (60\%).

Adapun hasil pre dan post test untuk mengetahui gambaran peningkatan pengetahuan responden setelah dilakukan promosi ksehatan adalah sebagai berikut.

Tabel 2. Distribusi Frekuensi pre dan post test pengetahuan responden 


\begin{tabular}{|c|c|c|c|c|c|}
\hline $\begin{array}{l}\text { No. } \\
\text { Respon } \\
\text { den }\end{array}$ & $\begin{array}{l}\text { Nilai } \\
\text { Pre test }\end{array}$ & $\begin{array}{c}\text { Nilai } \\
\text { Post } \\
\text { test }\end{array}$ & $\begin{array}{c}\text { Selisih } \\
\text { Pre dan } \\
\text { Post } \\
\text { test } \\
\end{array}$ & $\begin{array}{l}\text { Persen } \\
\text { tase }\end{array}$ & $\begin{array}{l}\text { Keterang } \\
\text { an }\end{array}$ \\
\hline 1. & 100 & $\begin{array}{c}10 \\
0\end{array}$ & 0 & $0 \%$ & Tetap \\
\hline 2. & & $\begin{array}{c}10 \\
0\end{array}$ & 0 & $0 \%$ & Tetap \\
\hline 3. & & $\begin{array}{c}10 \\
0\end{array}$ & +20 & $25 \%$ & Meningkat \\
\hline 4. & & $\begin{array}{c}10 \\
0\end{array}$ & 0 & $0 \%$ & Tetap \\
\hline $\begin{array}{l}5 . \\
6 .\end{array}$ & 80 & $\begin{array}{c}80 \\
10 \\
0\end{array}$ & $\begin{array}{r}0 \\
+20\end{array}$ & $\begin{array}{r}0 \% \\
25 \%\end{array}$ & $\begin{array}{c}\text { Tetap } \\
\text { Meningkat }\end{array}$ \\
\hline 7. & 60 & 80 & +20 & $33 \%$ & Meningkat \\
\hline $\begin{array}{l}8 . \\
9 .\end{array}$ & & $\begin{array}{l}70 \\
10\end{array}$ & $\begin{array}{r}+10 \\
0\end{array}$ & $\begin{array}{r}16 \% \\
0 \%\end{array}$ & $\begin{array}{l}\text { Meningkat } \\
\text { Tetap }\end{array}$ \\
\hline 10. & $\begin{array}{l}100 \\
80 \\
\end{array}$ & $\begin{array}{c}0 \\
10 \\
0 \\
\end{array}$ & +20 & $25 \%$ & Meningkat \\
\hline $\begin{array}{l}\text { Nilai } \\
\text { Terendah }\end{array}$ & 60 & 70 & 0 & $0 \%$ & \\
\hline $\begin{array}{l}\text { Nilai } \\
\text { Tertinggi }\end{array}$ & 100 & $\begin{array}{c}10 \\
0\end{array}$ & +20 & $33 \%$ & \\
\hline Rata-Rata & 84 & 93 & 9 & $12 \%$ & \\
\hline
\end{tabular}

Berdasarkan tabel di atas diketahui bahwa dari nilai terendah pada pre test adalah 60 sedangkan pada post test adalah 70 , nilai tertinggi pada pre dan post test adalah 100 , nilai rata-rata dari pre test adalah 84 sedangkan pada post test adalah 93. Hasil dari tabel diatas juga didapatkan informasi bahwa dari 10 responden terdapat 5 orang $(50 \%)$ yang tidak mengalami peningkatan pengetahuan dikarenakan tingkat pengetahuan yang dinilai dari pre dan post test sudah dalam taraf yang baik (diatas 80 poin) sedangkan responden lainnya $(50 \%)$ mengalami peningkatan pengetahuan yang cukup signifikan dimana peningkatan terendah adalah $16 \%$ dan peningkatan tertinggi adalah $33 \%$ dengan ratarata persentasi peningkatan pengetahuan adalah $12 \%$. Berdasarkan hasil ini dapat disimpulkan bahwa telah terjadi peningkatan pengetahuan dari responden terkait dengan pengelolaan sampah.
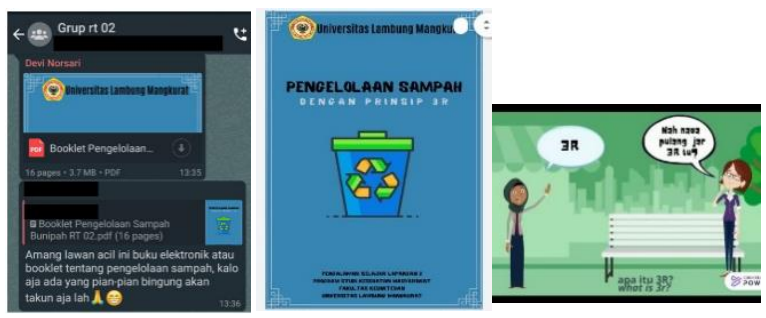

Gambar 1. Pengiriman media promosi kesehatan ke Whatsapp Group (kiri); Tampilan

cover booklet (tengah); Cuplikan video dengan URL: https://youtu.be/_ljjF-_E1xo (kanan)

Meningkat atau menetapnya pengetahuan dari masayrakat tersebut pastinya dikarenakan beberapa faktor, salah satunya adalah faktor eksternal. Dimana menurut Notoatmodjo (dalam Wawan dan Dewi, 2010), salah satu faktor eksternal dalam mempengaruhi tingkat pengetahuan adalah media penyampaian informasi yang digunakan. Melihat dari pemaparan hasil pre dan post test, penulis menelaah bahwa peningkatan pengetahuan terjadi karena responden telah menerima informasi dari materi yang sudah dibagikan melalui booklet dan video, Meski materi diberikan dalam bentuk audio dan visual hal tersebut tidak menjadi penghalang dalam proses transfer pengetahuan antara pemateri dan responden. Selain itu adanya komunikasi dua arah saat melakukan diskusi juga mempengaruhi akan peningkatan pengetahuan responden yang sebelumnya belum tahu menjadi tahu (Syamsuddin, 2017). Disisi lain juga terdapat masyarakat yang tidak mengalami peningkatan pengetahuan dimana hal tersebut juga terjadi akibat pengaruh eksternal seperti terkendala dalam melakukan pemutaran vidio ataupun dalam membaca booklet, selain itu juga adanya faktor internal dari masyarakat yang kurang maksmal dalam membaca maupun menonton vidio materi. Sehingga untuk kedepannya setiap dilakukan program penyuluhan daring, hendaknya di usahakan untuk dilakukan secara virtual meet, agar terjalin interaksi antara pemateri dan pendengar sehingga materi lebih mudah dipahami dan persentase peningkatan pengetahuan semakin tinggi.

\section{SIMPULAN DAN SARAN}

Hasil dari kegiatan penyuluhan secara yang dilakukan kepada masyarakat RT 02 Desa Bunipah, Kecamatan Aluh-Aluh, Kabupaten Banjar adalah tidak terdapat perbedaan yang signifikan antara pengetahuan responden pada saat pre test maupun post test mengenai konsep bank sampah. Tidak terdapat perbedaan yang signifikan antara pengetahuan responden pada saat pre test maupun post test mengenai pengelolaan sampah.

Terdapat perbedaan yang signifikan antara sikap responden pada saat pre test maupun post test mengenai pengelolaan sampah. Hasil persentase peningkatan pada setiap variabel kuisioner menunjukan pengetahuan mengenai konsep bank sampah meningkat sebanyak 10,7\%, Pada hasil pengetahuan mengenai pengelolaan sampah meningkat $9,33 \%$ dan sikap pengelolaan sampah 0,4\%. Meskipun demikian hasil tersebut masih belum memenuhi target luaran yaitu peningkatan sebanyak $70 \%$, hal ini dapat disebabka hasil pre-post masyarakat sudah baik, sehingga tidak banyak mengalami kenaikan yang signifikan. 
Diharapkan kepada Pemerintah Desa Bunipah dapat membuat kebijakan mengenai pengelolaan sampah agar dapat mengatasi permasalahan sampah yang terjadi khususnya di RT.02 Desa Bunipah. Kemudian Pemerintah Desa Bunipah juga dapat bekerja sama dengan instansi terkait seperti Puskesmas serta juga dengan tokoh adat, tokoh agama, dan tokoh masyarakat untuk mengadakan penyuluhan mengenai pengelolaan sampah yang baik dan benar agar memberikan pengetahuan tambahan kepada masyarakat untuk dapat mengatasi permasalahan sampah yang terjadi di RT.02 Desa Bunipah. Diharapkan kepada masyarakat RT.02 Desa Bunipah dapat menumbuhkan kesadaran mengenai pentingnya menjaga kebersihan lingkungan sekitar dengan tidak membuang sampah sembarangan dan melakukan pengelolaan sampah secara mandiri serta aktif dalam menambah pengetahuan dan memberikan edukasi kepada kerabat atau orang terdekat agar permasalahan sampah di RT.02 Desa Bunipah dapat teratasi.

\section{UCAPAN TERIMAKASIH}

Ucapan terima kasih disampaikan oleh penulis kepada seluruh pihak di Desa Bunipah, perangkat pemerintahan di Kecamatan AluhAluh dan Kabupaten Banjar. Ucapan terima kasih juga disampaikan kepada Universitas Lambung Mangkurat dan Program Studi Kesehatan Masyarakat serta Unit Pengampu Pengalaman Belajar Lapangan (UP-PBL). Terima kasih juga kepada Ihya Hazairin Noor, SKM., MPH, serta seluruh pihak yang tidak dapat disebutkan satu per satu yang telah turut membantu dalam penulisan laporan pengabdian ini.

\section{DAFTAR RUJUKAN}

Akbar, A. (2019). Consilium: Berkala Kajian Konseling Dan IImu Keagamaan. CONSILIUM. 6(2). 96-114.

Bibit, S. (2013). Efektivitas Penggunaan Media Pembelajaran Video Untuk Mencapai Tujuan Pembelajaran Ips Materi Letak Wilayah Indonesia Siswa Kelas VII SMPN 2 Banyudono. Artikel Publikasi.

Hapsari, C.M. (2013). Efektivitas Komunikasi Media Booklet "Anak Alami" Sebagai Media Penyampai Pesan Gentle Birthing Service. Jurnal E-Komunikasi. 1(3). 1-12.

Kahfi, A. (2017). Tinjauan terhadap pengelolaan sampah. Jurisprudentie. 4(1). $12-25$.

Mahyudin, R.P. (2017). Kajian Permasalahan Pengelolaan Sampah dan Dampak Lingkungan di TPA (Tempat
Pembuangan Akhir). Jurnal Teknik Lingkungan. 3(1). 66-74.

Rahmawati C, dkk. (2021). Penyuluhan Pengelolaan Sampah Plastik Menuju" Zero Waste Kampus Ummat". Selaparang Jurnal Pengabdian Masyarakat Berkemajuan. 3(2). 196-198.

Sabarudin, dkk. (2020). Efektivitas Pemberian Edukasi secara Online melalui Media Video dan Leaflet terhadap Tingkat Pengetahuan Pencegahan Covid-19 di Kota Baubau. Jurnal Farmasi Galenika (Galenika Journal of Pharmacy). 6(2): $309-318$.

Sari, L.A. (2017). Efektivitas Media Booklet Dan Leaflet Terhadap Pengetahuan Remaja Putri Tentang Dampak Kehamilan Remaja. Jurnal Pengabdian Masyarakat. 8(3). $14-24$

Syamsuddin, M., dkk. (2017). Faktor-faktor yang berhubungan dengan perilaku masyarakat dalam membuang sampah rumah tangga di Kali Mati Desa Babang tahun 2017. Jurnal Serambi Sehat. 10(3). 42-48.

Wardany, K., Sari, R.P., Mariana E. (2020). Sosialisasi pendirian "bank sampah" bagi peningkatan pendapatan dan pemberdayaan perempuan di Margasari. Jurnal Pengabdian Kepada Masyarakat. 4(2). 364-372.

Wati, F.R., dkk. (2021). Efektivitas kebijakan pengelolaan sampah berbasis tempat pengelolaan sampah terpadu $3 \mathrm{E}$ di Indonesia. PERSPEKTIF. 10(1). 195-203. 